\title{
A APRENDIZAGEM MATEMÁTICA DE SURDOS: enunciados que circulam nos Cadernos Cedes
}

\author{
DEAF STUDENTS AND MATHEMATICS LEARNING: statements found in Cader- \\ nos Cedes
} EL APRENDIZAJE MATEMÁTICO DE SORDOS: enunciados que aparecen en los
Cadernos Cedes

\author{
Daiane Kipper \\ Professora Mestra das redes estadual e municipal de educação de Santa Cruz do Sul. \\ daianekipper@hotmail.com \\ Janete Inês Müller \\ Professora Mestra do Instituto Federal de Educação, Ciência e Tecnologia Farroupilha. \\ Doutoranda em Educação na Universidade Federal do Rio Grande do Sul. \\ janeteim@hotmail.com \\ Cláudio José de Oliveira \\ Professor Doutor da Universidade de Santa Cruz do Sul - UNISC. \\ coliveir@unisc.br
}

RESUMO: Neste trabalho, estamos interessados em examinar um conjunto de artigos publicados no número noventa e um (91) dos Cadernos Cedes, que abordam a aprendizagem de matemática por crianças e adolescentes surdos. Para o exercício analítico, na perspectiva foucaultiana, apoiamo-nos na ferramenta teórico-metodológica do enunciado. Para tal, discutimos o material empírico desta investigação, considerando a metodologia, o referencial teórico e os resultados produzidos pelos autores em seus artigos. O material analisado apresentou aproximações em relação à metodologia das investigações, visto que o desenvolvimento das pesquisas dá-se em ambientes escolares, por meio de atividades com alunos, tendo como foco crianças e adolescentes. Das análises, emergiram enunciados relacionados à aprendizagem matemática por crianças e adolescentes surdos, tais como: as crianças surdas estão atrasadas em relação às ouvintes; a exposição à língua de sinais melhora o desempenho da criança surda; existem experiências educacionais prévias em contextos informais; a visualidade é fundamental no ensino/ aprendizagem da matemática; há uma emergência de criação de sinais nessa área. Nesse sentido, mesmo que as pesquisas sejam desenvolvidas com base em diferentes perspectivas teóricas, são recorrentes os enunciados que posicionam as crianças e jovens surdos como 'atrasados' em relação aos ouvintes de mesma faixa etária, e isso por não atenderem a um padrão cultural pré-determinado, sobretudo pela Matemática Escolar da Modernidade.

PALAVRAS-CHAVE: Educação de surdos. Cadernos Cedes. Matemática.

ABSTRACT: In this paper, we are interested in examining a group of papers published in Cadernos Cedes number ninety-one (91), which addresses mathematics learning by deaf children and adolescents. For such analytical exercise, grounded on the Foucauldian perspective, we have been supported by the theoretical-methodological tool of enunciation. We have discussed the empirical material of this investigation by considering the methodology, theoretical references and results produced by the authors in their papers. The analyzed material showed approximations in terms of methodology, since the researches were carried out in school settings by means of activities with students, with a focus on children and adolescents. From the analyses, some enunciations related to mathematics learning by deaf children and adolescents have emerged, such as the following: deaf children lag behind their hearing peers; exposure to sign language improves deaf children's performance; there are previous educational experiences in informal contexts; visualization is fundamental in mathematics teaching/learning; there has been an increase in signs in this area. In this sense, even though the researches were based on different theoretical perspectives, enunciations positioning deaf children and adolescents as 'delayed' in comparison with same-age hearing peers are recurrent, as deaf students do not fit the cultural standard that has been predetermined by School Mathematics in Modernity. KEYWORDS: Deaf education. Cadernos Cedes. Mathematics.

Artigo recebido em janeiro de 2015

Aprovado em março de 2015 
RESUMEN: En este trabajo, estamos interesados en examinar un conjunto de artículos publicados en el número noventa y uno (91) de los Cadernos Cedes, que tratan del aprendizaje de matemáticas por niños y adolescentes sordos. Para el ejercicio analítico, en la perspectiva foucaultiana, nos apoyamos en la herramienta teórico metodológica del enunciado. Para eso, discutimos el material empírico de esta investigación, considerando la metodología, el referencial teórico y los resultados producidos por los autores en sus artículos. El material analizado presentó aproximaciones en relación a la metodología de las investigaciones, ya que el desarrollo de las pesquisas ocurre en ambientes escolares, a través de actividades con alumnos, teniendo como enfoque niños y adolescentes. De los análisis surgieron enunciados relacionados al aprendizaje matemático por niños y adolescentes sordos, tales como: los niños sordos están retrasados en relación a los oyentes; la exposición a la lengua de señas aumenta el desempeño del niño sordo; hay un retraso de los estudiantes sordos en matemáticas; existen experiencias educacionales previas en contexto informales; la visualidad es fundamental en la enseñanza/aprendizaje de la matemática; hay una emergencia de creación de señas en esa área. En ese sentido, aunque las pesquisas sean desarrolladas con base en distintas perspectivas teóricas, son recurrentes los enunciados que posicionan los niños y jóvenes sordos como 'retrasados' en relación a los oyentes de misma franja etaria; y eso por no hacer parte de un patrón cultural predeterminado principalmente por la Matemática Escolar de la Modernidad.

PALABRAS CLAVE: Educación de sordos. Cadernos Cedes. Matemáticas. 
A APRENDIZAGEM MATEMATICA | Daiane Kipper, Janete Inês Müller e Cláudio José de Oliveira

\section{1 | TERRITÓRIOS INVESTIGATIVOS}

Os movimentos surdos possibilitaram a conquista e a garantia de seus direitos linguísticos, políticos e educacionais, sobretudo a partir do reconhecimento da Língua Brasileira de Sinais (Libras) como língua oficial no Brasil. Diante disso, o acesso e a permanência de surdos na Educação Básica e no Ensino Superior tensionam os processos de inclusão escolar desses sujeitos. Provocados à reflexão, professores e pesquisadores debatem a aprendizagem dos alunos surdos nas diferentes áreas do conhecimento.

Neste trabalho, detemo-nos à área da Matemática $^{1}$, visto que, como docentes e/ou pesquisadores, estamos envolvidos com o seu ensino e com a educação de surdos. Sendo assim, tomamos os Cadernos Cedes $^{2}$ como material de análise, os quais reúnem, no número noventa e um (91), publicado no ano de 2013, discussões sobre a aprendizagem de matemática por crianças e adolescentes surdos. Esse número temático contempla um conjunto diversificado de pesquisadores, de universidades brasileiras e europeias, com uma variedade de métodos de pesquisa e de perspectivas teóricas.

Para o exercício analítico, na perspectiva foucaultiana, apoiamo-nos na ferramenta teóricometodológica do enunciado. Visto que "a verdade mais elevada já não residia mais no que era o discurso, ou no que ele fazia, mas residia no que dizia" (FOUCAULT, 1998, p. 15, grifo do autor), há um deslocamento da verdade como enunciação (que remete ao ato) para o próprio enunciado (resultado do ato). Nas obras A arqueologia do saber (2004) e em As palavras e as coisas (1999), Michel Foucault define o enunciado com base na espisteme ${ }^{3}$, e não nas questões linguísticas, ou seja, ele se detém às condições de possibilidades de uma determinada época. Desse modo, em um determinado tempo e espaço, alguns enunciados são possíveis e outros não (SILVA, 2000), pois segundo Foucault (2004, p. 31-32).

[...] um enunciado é sempre um acontecimento que nem a língua nem o sentido podem esgotar inteiramente. Trata-se de um acontecimento estranho, por certo: inicialmente porque está ligado, de um lado, a um gesto de escrita ou à articulação de uma palavra, mas, por outro lado, abre para si mesmo uma existência remanescente no campo de uma memória, ou na materialidade dos manuscritos, dos livros e de qualquer forma de registro; em seguida, porque é único como todo acontecimento, mas está aberto à repetição, à transformação, à reativação; finalmente, porque está ligado não apenas a situações que o provocam, e a consequências por ele ocasionadas, mas, ao mesmo tempo, e segundo uma modalidade inteiramente diferente, a enunciados que o precedem e o seguem.

Nessa perspectiva, um sujeito social, que produz um enunciado, não pode ser entendido como uma entidade que existe fora e independentemente do discurso. Os enunciados posicionam os sujeitos que os produzem e os sujeitos a quem dirigidos, de modo que descrever uma formulação

\footnotetext{
1 Utilizamos inicial maiúscula em 'Matemática' quando se tratar de substantivo próprio, como, por exemplo, em área/ campo de conhecimento ou disciplina do currículo escolar. Entretanto, respeitamos - e portanto não alteramos - os usos feitos pelos autores aqui citados.

${ }^{2}$ Os Cadernos Cedes apresentam publicações de caráter temático, as quais se dirigem a profissionais e pesquisadores da Educação. São editados desde 1980, mantendo de 3 a 6 novos títulos por ano. Neste trabalho, são analisados os artigos do volume 33, número 91 , correspondente ao período de setembro a dezembro 2013, os quais apresentam como temática a aprendizagem de matemática de crianças e adolescentes surdos.

${ }^{3} \mathrm{Na}$ nomenclatura utilizada por Michel Foucault, espisteme é compreendido como um conjunto de regras e princípios predominantes em um determinado período histórico, que possibilita que determinadas coisas sejam ditas e outras não (SILVA, 2000).
} 
enunciado não consiste em analisar a relação entre o autor e o que ele diz (ou quis dizer, ou disse sem querer), mas em determinar que posição pode e deve ser ocupada por qualquer indivíduo, para que ele seja sujeito dela. Conforme Fischer (2001), descrever um enunciado é dar conta dessas especificidades, apreendendo-o como acontecimento, como algo que irrompe em certo tempo e lugar; situar um emaranhado de enunciados em uma organização está relacionado ao fato de pertencerem a uma certa formação discursiva. Dialogando com Foucault (2004), o conjunto de enunciados que se apoia em uma mesma formação discursiva constitui o discurso.

Neste estudo que tematiza pesquisas sobre a aprendizagem matemática de alunos surdos, condições de possibilidades estão produzindo enunciados. Descrever enunciados e suas relações implica operar sobre a superfície dos textos; importa explorar ao máximo os materiais na medida em que são uma produção histórica e política, escapando da fácil interpretação do que estaria 'por trás' dos documentos; é preciso ficar no nível da existência das palavras, das coisas ditas, trabalhando arduamente com o próprio discurso. Ao operar sobre os enunciados, é possível construir unidades arquitetônicas; ou melhor, produzir monumentos, buscando entender o porquê de alguns ditos, em determinadas situações, em um tempo e lugar, não sendo eles, portanto, diferentes.

O olhar analítico ao material empírico desta investigação possibilitou observar a recorrência de alguns 'ditos' em relação à aprendizagem matemática por crianças e adolescentes surdos, tais como: as crianças surdas estão atrasadas em relação a crianças ouvintes; a exposição à língua de sinais aumenta o desempenho da criança surda; existem experiências educacionais prévias em contexto informais; a visualidade é fundamental no ensino/aprendizagem da matemática; há uma emergência de criação de sinais nessa área. Dada a complexidade de material empírico e os limites de um texto como este, aqui analisamos enunciados que instituem um suposto 'atraso' das crianças e dos jovens surdos em relação aos ouvintes. Cabe acrescentar que esse 'dito', por sua vez, é construído na relação com outros, que discutem a visualidade, o uso da língua de sinais e as experiências surdas.

Assim, prosseguimos com a apresentação do material empírico desta investigação, tendo em vista a metodologia, o referencial teórico e os resultados produzidos pelos autores dos artigos analisados. Na sequência, detemo-nos à análise dos enunciados, apresentando, por fim, algumas problematizações acerca da temática aqui proposta.

\section{2 | AS PESQUISAS NOS CADERNOS CEDES: perspectivas e resultados}

O primeiro artigo dos Cadernos Cedes, de Nunes et al. (2013), intitulado Promovendo a compreensão da composição aditiva em crianças surdas, apresenta um estudo comparativo da composição aditiva dos números, analisando a compreensão das crianças surdas com base na pesquisa realizada com crianças ouvintes. Na investigação de Nunes et al. (2013), na perspectiva piagetiana, a metodologia é constituída a partir de duas etapas: na primeira, comparou-se a compreensão de composição aditiva entre crianças surdas e ouvintes da mesma idade; na segunda, realizou-se uma intervenção para avaliar a possibilidade de melhorar a compreensão das crianças surdas.

Para a realização da primeira etapa, participaram crianças do primeiro ano escolar: vinte e oito surdas (com idade média de 6 anos e 5 meses) e setenta e sete ouvintes (em torno de 6 anos e 2 meses). Por meio desse estudo, os pesquisadores concluíram que a maioria das crianças ouvintes ingressa na escola com uma boa base para a compreensão do sistema numérico decimal, visto que o seu desempenho na 'Tarefa de Compra' demonstrou a compreensão da composição aditiva. Já as crianças surdas apresentaram um despreparo na compreensão, tanto do sistema de 
numeração quanto na escrita dos números. Na segunda etapa da pesquisa, participaram vinte e duas crianças surdas, que estavam no primeiro e segundo ano, em escolas da Inglaterra, com idade média de 6 anos e 10 meses. Nesse caso, observou-se que as crianças surdas estão atrasadas quanto à sua compreensão da composição aditiva, demostrando que um período de ensino pode ser eficiente para melhorar o seu desempenho (NUNES et al., 2013).

Barbosa (2013), no texto intitulado Habilidades matemáticas iniciais em crianças surdas e ouvintes, investigou o conhecimento de procedimentos e conceitos matemáticos em crianças surdas da Educação Infantil. Para isso, realizou um estudo quantitativo com análise comparativa de variáveis, apresentando, como participantes da pesquisa, quatro grupos de crianças ouvintes e surdas, com idade entre 5 e 6 anos. Os resultados do estudo revelaram que as diferenças de desempenho entre crianças surdas e ouvintes estão relacionadas às questões linguísticas; também considerou que o fracasso na matemática apresentado pelas crianças surdas e filhas de pais ouvintes está relacionado ao pouco acesso a experiências que antecedem a vida escolar, as quais envolvem a contagem, por exemplo; já as crianças ouvintes têm experiências na vivência com a mesma língua de seus familiares. Além disso, o estudo apontou que as crianças surdas apresentaram um conhecimento superior na manipulação de informações visuais e espaciais, o que está relacionado à sua diferença linguística; por isso, segundo a pesquisadora, é importante que as crianças surdas estejam expostas à língua de sinais, o mais cedo possível.

O artigo Expressando generalizações em Libras: álgebra nas mãos de aprendizes surdos, escrito por Fernandes e Healy (2013), tem por objetivo identificar como aprendizes que têm a Língua Brasileira de Sinais (Libras) como primeira língua expressam generalizações matemáticas. $\mathrm{Na}$ perspectiva socioconstrutivista, foram realizadas atividades com uma turma do nono ano do Ensino Fundamental de jovens e adultos, cujas idades variavam entre 18 e 31 anos. As pesquisadoras consideram o aprendizado da matemática em Libras como um desafio, posicionando a língua como cerne da questão, pois, durante o desenvolvimento da pesquisa, houve alguns impasses quanto à interpretação da língua escrita nas atividades realizadas pelos aprendizes. Elas também destacam a emergência de um pensamento algébrico nas práticas matemáticas, pois foi possível perceber que os aprendizes surdos faziam reflexões, utilizando-se do pensamento algébrico, mas sem recorrer à língua algébrica convencional.

Em Observando estratégias e buscando soluções: a resolução de operações por adolescentes surdos, Fernández-Viader e Fuentes (2013) apresentam uma investigação sobre as estratégias de resolução de operações envolvendo a adição e a subtração. O referencial teórico apoia-se no paradigma socioconstrutivista; a metodologia consiste em um estudo etnográfico e os sujeitos da pesquisa foram sete adolescentes, surdos profundos, pré-linguísticos, com idades entre 12 e 15 anos, de uma escola de Barcelona. Com base nos resultados, as pesquisadoras puderam inferir que há um atraso no rendimento de crianças e jovens surdos em relação aos ouvintes na área da Matemática, assim como os estudantes que tiveram maior experiência em Língua de Sinais da Catalunha (LSC) costumam utilizá-la na resolução de problemas matemáticos. Outra questão suscitada pelo estudo é a escassez de experiências educacionais antes da escolarização, o que ocorre com estudantes surdos e filhos de pais ouvintes, incidindo em sua aprendizagem matemática. O estudo apontou também a importância da visualidade no ensino, tendo em vista que, para calcular, do mesmo modo que uma pessoa ouvinte recorre à fala do numeral, a pessoa surda recorre à imagem do numeral. Além disso, afirmou-se que a interpretação dos tipos de erro e o conhecimento das estratégias utilizadas pelos alunos surdos, a fim de realizarem operações, constituem-se aspectos relevantes para a qualificação dos professores. 
A APRENDIZAGEM MATEMATICA | Daiane Kipper, Janete Inês Müller e Cláudio José de Oliveira

Na pesquisa $\mathrm{O}$ uso do Multiplano 4 por alunos surdos e o desenvolvimento do pensamento geométrico, desenvolvida por Arnoldo Junior, Ramos e Thoma (2013), é analisada a contribuição do Multiplano para a aprendizagem de geometria por alunos surdos. O referencial teórico apoiase na perspectiva foucaultiana, apresentando um estudo de caso de cunho etnográfico. O referido trabalho contou com a participação de dois alunos surdos fluentes em Libras, do Ensino Fundamental de uma escola de surdos da Região Metropolitana de Porto Alegre (RS): um menino, de 18 anos, filho de pais ouvintes, que sabiam Libras; e uma mulher, de 35 anos, que morava com a avó, que não sabia Libras. O estudo teve a duração de 17 encontros, sendo que, em 10 deles, foi efetivamente utilizado o Multiplano, e as atividades desenvolvidas com esse recurso abordaram o conteúdo de geometria.

De acordo com essa investigação, afirma-se que os surdos têm enfrentado barreiras comunicativas em relação ao ensino da matemática, pois conceitos específicos dessa área não têm sinais em Libras. Nesse sentido, o uso do material concreto tem sido empregado por pesquisadores para o desenvolvimento de itens lexicais da Libras. Assim, o Multiplano apresenta-se como um recurso visual para criação dos classificadores ${ }^{5}$ e se constitui um imperativo para a formação e a estruturação do pensamento dos sujeitos surdos. Nesse aspecto, a pesquisa apontou o Multiplano como um recurso didático adequado às necessidades da cultura surda para a aprendizagem matemática. Por fim, os pesquisadores apontam que "não só em matemática, mas também em outras áreas do conhecimento, é eminente a criação de sinais, assim como é emergente a difusão desses sinais para a Educação" (ARNOLDO JUNIOR; RAMOS; THOMA, 2013, p. 403).

Em Uma intervenção em contagem com duas crianças surdas, Vargas e Dorneles (2013) apontaram que as crianças surdas e filhas de pais surdos estão em vantagem para aprender conceitos numéricos, se comparadas a crianças surdas e filhas de pais ouvintes. O referencial teórico apoia-se na perspectiva cognitivista; a metodologia contou com um estudo de caso, tendo a participação de duas crianças surdas de 6 anos de idade: uma é filha de pais ouvintes; e a outra é filha de pais surdos. A pesquisa focou um programa de intervenções e seus resultados, bem como uma exploração do processo observado. Foram realizadas três avaliações de ambas as crianças: pré-teste (realizado antes das intervenções pedagógicas); teste intermediário (realizado ao final da última avaliação) e pós-teste (realizado três meses após a última intervenção). As intervenções aconteceram em oito sessões, realizadas ao longo de quatro semanas. Cada criança trabalhou de forma individual, junto a uma professora experiente na educação de surdos.

Durante o desenvolvimento das atividades, foi investigada a composição aditiva do número, bem como a sua melhoria no uso de procedimentos econômicos de contagem, na resolução de problemas. O estudo de Vargas e Dorneles (2013) constatou que o conhecimento da composição aditiva vem acompanhado do conhecimento matemático informal, o qual se processa em relações sociais extraescolares, sem intencionalidade. Compreende-se que o conhecimento intuitivo é fundamental para a aprendizagem da matemática formal; também as crianças alcançaram níveis semelhantes tanto no uso de procedimentos de contagem, quanto na compreensão aditiva do número e no aumento do campo numérico. Nesse aspecto, ser nativo da Libras não foi um fator decisivo para determinar o quanto as crianças se beneficiaram da intervenção, bem como a aquisição da linguagem não se apresentou como um fator facilitador na evolução da aquisição do conceito numérico.

\footnotetext{
${ }^{4} \mathrm{O}$ kit Multiplano é composto por duas placas: uma retangular e outra circular. O dispositivo conta com elásticos, pinos, hastes e outros componentes, usados para ensinar conceitos matemáticos para alunos de todos os níveis de ensino: fundamental, médio e superior (ARNOLDO JUNIOR; RAMOS; THOMA, 2013, p. 403).

${ }^{5}$ Os classificadores permitiram estabelecer relações entre a língua portuguesa e a língua de sinais, como também um elo comunicativo entre a professora e os alunos (ARNOLDO JUNIOR; RAMOS; THOMA, 2013).
} 
A APRENDIZAGEM MATEMATICA | Daiane Kipper, Janete Inês Müller e Cláudio José de Oliveira

E, por último, os Cadernos Cedes apresentam a seção Caleidoscópio (2013), que foi escrita pelas professoras norte-americanas Karen L. Kritzer, da Kant State Universtity, e Cláudia M. Pagliaro, da Michigan State University. Nessa seção, as professoras realizam uma descrição do que já foi pesquisado sobre a aprendizagem matemática de crianças surdas e o que ainda é preciso investigarem nessa área. Entretanto, esse texto não compõe o material de análise desta pesquisa, visto que nos detemos apenas aos artigos dos Cadernos Cedes.

\section{3 | 0 ‘ATRASO’ NA APRENDIZAGEM MATEMÁTICA DE CRIANÇAS E JOVENS SURDOS}

Os artigos analisados apresentaram recorrências em relação à metodologia das investigações, visto que o desenvolvimento das pesquisas acontece em ambientes escolares, por meio de atividades matemáticas com alunos surdos, tendo como foco crianças e adolescentes. As pesquisas de Nunes et al. (2013) e Barbosa (2013) apresentam um estudo comparativo entre surdos e ouvintes, evidenciando o 'atraso' dos surdos em relação aos ouvintes. Já os estudos de Fernandes e Healy (2013), Fernández-Viader e Fuentes (2013), Arnoldo Jr., Ramos e Thoma (2013) apresentam um estudo que se pauta no desenvolvimento de atividades visuais na matemática, tendo como sujeitos da pesquisa somente alunos surdos. O trabalho de Vargas e Dorneles (2013) apresenta um estudo de caso para comparar se há vantagem no aprendizado de conceitos numéricos por um surdo e filho de pais surdos, em relação a um surdo e filho de pais ouvintes.

Em geral, no exercício analítico desenvolvido nesta investigação, recorrentes foram os enunciados que remetem ao 'atraso' das crianças e jovens surdos, sobretudo em relação aos ouvintes, como podemos perceber no excerto ${ }^{6}$ selecionado e a seguir apresentado:

A maioria das crianças ouvintes começa a escola com uma boa base para compreender o sistema de numeração decimal e sua escrita usando o valor posicional, pois seu desempenho na Tarefa de Compra demonstra sua compreensão aditiva. Em contraste, a maioria das crianças surdas não está preparada para compreender o sistema de numeração e a escrita dos números. [...] Esse atraso não é esperado, tendo em vista que a inteligência não verbal, que está correlacionado à aprendizagem em matemática, não mostra diferenças entre surdos e ouvintes. (NUNES et al., 2013, p. 325-331, grifo nosso).

Nesse sentido, percebemos que as pesquisas apontam para uma equiparação entre surdos e ouvintes no que remete à sua aprendizagem, tomando o modelo ouvinte como referente, ou seja, como 'uma régua' para medir a aprendizagem das crianças e jovens surdos nos diferentes períodos da escolarização (da Educação Infantil ao Ensino Médio). O 'atraso' das crianças e jovens surdas nesta área do conhecimento determina quem está apto ou não, em determinada faixa etária, a compreender determinados conteúdos matemáticos. Segundo Knijnik et al. (2012, p. 84)

\footnotetext{
A Matemática que ensinamos na escola tem servido de modo muito exemplar para dizer que "ela, sim, é difícil", que é "para poucos". Com isso, ela mesmo estabelece uma hierarquia que a coloca em um lugar muito privilegiado, um lugar que acaba influindo sobre quem irá adiante nos estudos, que é "inteligente" e quem está de fora desse círculo tão restrito dos "que sabem".
}

\footnotetext{
${ }^{6}$ Os excertos dos Cadernos Cedes, que constituem o corpus empírico deste trabalho, são apresentados em itálico neste texto, de modo a diferenciá-los das demais citações.
} 
Determinando assim o tempo e o quê cada sujeito deve aprender, desconsiderando as diferenças culturais, elege-se um modelo a ser seguido como padrão; essa norma é balizadora para os demais alunos, ou seja, quem nela não se enquadrar necessita ser corrigido. "O indivíduo a ser corrigido vai aparecer nesse jogo, nesse conflito, nesse sistema de apoio que existe entre a família e, depois, a escola, a oficina, a rua, o bairro, a paróquia, a igreja, a polícia, etc." (FOUCAULT, 2001b, p. 72). A Matemática, como disciplina escolar, apresenta esta função: esquadrinhar os indivíduos, ditando-Ihes os conteúdos e em que tempo devem ser aprendidos. Esse tempo é um único possível: trata-se do tempo em que o sujeito normal ${ }^{7}$ - neste caso, o ouvinte - aprende. Para Skliar (2003, p. 38)

Existe um tempo do outro que é conhecido e reconhecido pela mesmidade como o único tempo possível; um tempo do outro que foi inventado, domesticado, usurpado, ordenado, traduzido e governado a partir das metáforas temporais da repetição, do constante, do clínico, do linear, do circular. Assim como existe também um tempo do outro que (nos) é irreconhecível, indefinível, inominável, ingovernável.

Portanto, reduzimos o outro a um único tempo; o tempo que deve ser seguido como uma regra; o tempo nos dita as regras. O tempo encerra todos em uma mesma lógica; logo, quem não consegue se adequar a essa lógica acaba por ser nomeado como 'atrasado'. O 'atrasado' apresenta-se como uma representação recorrente, em enunciações acerca de crianças e jovem surdos, em contextos escolares. O 'atraso' também é apontado na pesquisa de Barbosa (2013), afirmando-se que as crianças surdas apresentam um desempenho inferior em relação às crianças ouvintes, como se observa a seguir:

[...] dados advindos de pesquisas acadêmicas que apontam para um fracasso escolar na área da matemática em crianças surdas. Vários estudos acadêmicos e levantamentos estatísticos [...] têm mostrado que crianças surdas apresentam um desempenho inferior, ou baixo da média, na área da matemática em comparação com as crianças ouvintes, de mesma série e idade, que se desenvolvem tipicamente. (BARBOSA, 2013, p. 334, grifo nosso).

As crianças surdas no geral tiveram um desempenho inferior em relação às crianças ouvintes mais velhas e às crianças ouvintes que frequentam a escola infantil privada. Mas não em relação às crianças mais novas da escola pública. [...] tanto crianças surdas quanto as ouvintes das classes sociais menos privilegiadas estão em risco de apresentarem dificuldades em matemática nos anos iniciais de aprendizagem das crianças surdas e das crianças ouvintes. (BARBOSA, 2013, p. 345, grifo nosso).

Podemos ainda inferir que o desempenho do aluno ouvinte de escola privada apresenta-se como uma norma, o padrão a ser seguido. Os que não seguem esse padrão são nomeados como sujeitos de 'desempenho inferior' ou 'com dificuldades de aprendizagem'. Aponta-se, ainda, que alguns conhecimentos devem ser desenvolvidos em uma determinada série e idade, tendo em vista os padrões estimados para um sujeito ouvinte. Tais verdades são legitimadas por 'estudos acadêmicos e levantamentos estatísticos', como é possível perceber nos trechos anteriormente apresentados.

\footnotetext{
${ }^{7}$ A normalização disciplinar consiste em primeiro colocar um modelo, um modelo ótimo que é construído em função de certo resultado; e as operações de normalização disciplinar consistem em procurar as pessoas, os gestos, os atos conformes a esse modelo; é normal quem é capaz de se conformar com essa norma; o anormal não é capaz. Em outros termos, o que é fundamental e primeiro na normalização disciplinar não é o normal e o anormal, mas, sim, a norma (FOUCAULT, 2008, p. 75).
} 
Evidencia-se, portanto, a existência de um tempo que é do outro, e aquele que não se deixar aprisionar por um tempo único e igual para todos. Esse tempo não existe desde sempre, mas foi produzido pela Modernidade, que impõe a sua ordem e aprisiona tudo ao seu entorno. Nesse tempo, quem não se permite prender é nomeado como 'atrasado', com 'desenvolvimento inferior' e com 'dificuldades de aprendizagem', ou seja, um sujeito que não se enquadra em tipo específico de sujeito aprendente.

Concordando com Skliar (2003, p. 39),

Não existe nada humano fora do tempo e não existe nenhum tempo fora do humano. Entretanto: existe um único tempo dentro do humano e um único humano dentro do tempo? Com certeza, não. E dessa multiplicação ou fração ou dilatação entre temporalidade e o humano, surge a perplexidade desses tempos. [...] Perplexidade que irrompe para também nos desvanecer, para criar uma temporalidade outra.

Além da temporalidade, que é normatizada nos enunciados que compõem nosso material empírico, a forma de se relacionar com a linguagem matemática apresenta as suas convenções e normas. No excerto transcrito a seguir, embora a comparação entre surdos e ouvintes não seja tão evidente, percebemos que os sujeitos surdos são posicionados como aprendizes que 'ainda não recorrem à língua algébrica convencional'; e esta é estabelecida a partir de uma cultura ouvinte, a qual se difere da cultura surda pela língua utilizada. Nesse sentido, no texto de Fernandes e Healy (2013, p. 656, grifo nosso), publicado nos Cadernos Cedes, afirma-se "[...] há evidências nas generalizações expressas por eles que refletem um modo de pensar algebricamente, mesmo que ainda não recorram à língua algébrica convencional". Assim como nas demais áreas e disciplinas, também na Matemática Escolar, há convenções para o conhecimento; não só em relação ao que é posicionado como conhecimento matemático, assim como em relação à forma como este deve circular, seus padrões e normas de uso. Com base em estudos de Foucault (2001a, p. 12), percebemos as relações entre a verdade e o poder, como também a produção de verdades:

\footnotetext{
O importante, creio, é que a verdade não existe fora do poder ou sem poder (não é - não obstante um mito, de que seria necessário esclarecer a história e as funções - a recompensa dos espíritos livres, o filho das longas solidões, o privilégio daqueles que souberem se libertar). A verdade é deste mundo; ela é produzida nele graças a múltiplas coerções e nele produz efeitos regulamentados de poder. Cada sociedade tem seu regime de verdade, sua "política geral" de verdade: isto é, os tipos de discurso que ela escolhe e faz funcionar como verdadeiros; os mecanismos e as instâncias que permitem distinguir os enunciados verdadeiros dos falsos, a maneira como se sanciona uns e outros; as técnicas e os procedimentos que são valorizados para a obtenção de verdade: o estatuto daqueles que têm o encargo de dizer o que funciona como verdadeiro.
}

Nessa esteira de pensamento, a Matemática Escolar vem instituir o que pode ser considerado ou desconsiderado como língua convencional, para determinados conhecimentos. No caso do conhecimento algébrico, a pesquisa de Fernandes e Healy (2013) descreve o pensamento algébrico dos sujeitos surdos como não convencional, ou seja, não atende aos padrões já instituídos pelos regimes de verdade que formulam essa área do conhecimento. Há uma forma convencional de se escrever a matemática, a qual está dentro de um regime de verdade. Mesmo que o excerto anteriormente apresentado não discuta o 'atraso' do aluno surdo, ele afirma que o mesmo não utiliza o pensamento algébrico convencional; logo, ele não atende ao padrão pré-estabelecido e convencionado por/para o ouvinte. 
Em outros artigos, observamos não apenas os enunciados sobre o 'atraso' das crianças surdas, como também a sua 'inferior habilidade' em relação às ouvintes. Isso porque as crianças ouvintes têm acesso a conhecimentos matemáticos transmitidos culturalmente, e o mesmo não ocorre com as crianças surdas. Logo, a norma ouvinte continua sendo o imperativo, tanto para o tempo de aprendizagem quanto em relação ao conhecimento cultural dos alunos surdos. No caso dos 'aspectos culturalmente transmitidos do conhecimento matemático', que servem de base para aprendizagem dos conhecimentos relacionados à Matemática Escolar, as crianças ouvintes também são tomadas como referência, como evidenciamos nos próximos excertos selecionados.

"Numerosas pesquisas já relataram o atraso do rendimento de crianças e jovens surdos em relação a seus pares ouvintes na área de matemática e tentaram averiguar as causas." (FERNÁNDEZ-VIADER; FUENTES, 2013, p. 370, grifo nosso). "Nosso trabalho confirma o resultado dos estudos anteriores sobre o atraso dos estudantes surdos na área de matemática." (FERNÁNDEZ-VIADER; FUENTES, 2"013, p. 381, grifo nosso). "[...] elas são menos hábeis que as crianças ouvintes para aprender os aspectos culturalmente transmitidos do conhecimento matemático." (FERNÁNDEZ-VIADER; FUENTES, 2013, p. 382, grifo nosso).

Corroborando nossa argumentação acerca do posicionamento do sujeito surdo em relação à aprendizagem matemática, nos próximos excertos, evidenciamos a desvantagem da criança surda em relação à criança ouvinte, sobretudo em relação à aquisição de conhecimentos matemáticos. Aponta-se, inclusive, que as crianças surdas devem aprender determinados conceitos numéricos tão cedo quanto crianças ouvintes. Assim, desconsidera-se o conhecimento que a criança surda desenvolve ao longo da sua infância, por se diferenciar culturalmente da criança ouvinte.

"Temos poucas informações disponíveis sobre quando as crianças surdas começam a usar tais princípios. Algumas pesquisas mostram que estas crianças estão em desvantagem na aquisição dos conceitos matemáticos, se comparadas com seus pares ouvintes." (VARGAS; DORNELES, 2013, p. 412, grifo nosso). "[...] independente do momento da aquisição da linguagem de sinais, as crianças surdas precisam ser atendidas nas suas necessidades específicas para que possam construir os primeiros conceitos numéricos tão cedo quanto as crianças ouvintes." (VARGAS; DORNELES, 2013, p. 425, grifo nosso).

De outro modo, discutimos, ainda, condições de possibilidades para se encontrar outras respostas nos enunciados das pesquisas que compõem os Cadernos Cedes. Se os artigos tomam como referência problematizar a aprendizagem de matemática, por sujeitos surdos, eles também nos trazem a possibilidade de discutir o nomeado 'atraso' como uma questão que envolve o visual e o escrito no componente curricular de Matemática. Entre os trabalhos analisados, o estudo de Arnold, Ramos e Thoma (2013) aborda a questão da visualidade, no âmbito da educação de surdos, visto que, para os autores, recursos visuais são produtivos, tanto para ouvintes quanto para surdos. Em relação à visualidade, no referido texto, afirma-se:

Como os recursos visuais podem contribuir para o desenvolvimento de sinais em Libras? Percorrendo assertivas conclusivas deste estudo, contata-se que a visualidade pode ser proporcionada pelo uso de materiais concretos que denotem os conceitos que estão sendo estudados. Um signo transpõe-se para outo signo, neste caso linguístico, pelo processo de internalização, uma ação externa convertida ação interna, que depois conduzirá as ações e decisões dos sujeitos [...], como já mencionamos. Em contagem, por exemplo, os alunos necessitavam recorrer à visualização de sua sinalização para associar o número ao seu significado, da mesma forma como os ouvintes fazem quando contam empregando os dedos (assertiva 5). (ARNOLDO JUNIOR; RAMOS; THOMA, 2013, p. 402, grifos nossos). 
A visualidade é uma forma de os surdos interagirem com o conhecimento; entretanto, no contexto escolar, ainda há uma valorização da escrita, que adquire supremacia inclusive em se tratando do uso da Libras por surdos. Assim como nos estudos de Knijnik et al. (2012) realiza-se uma discussão entre o oral e o escrito em relação a outros grupos culturais, abre-se a possibilidade de realizar, de forma análoga, uma discussão entre o visual e o escrito no contexto da educação bilíngue ${ }^{8}$ para surdos. Ao entender,

[...] a educação matemática como um campo do currículo também implicado na construção de subjetividades, produzidas não em um terreno neutro e desinteressado, mas, ao contrário, em um terreno onde certos grupos acabam por impor o seu modo de raciocinar e a sua matemática como a única racionalidade possível, talvez possamos problematizar, por exemplo, a relação entre a escrita e a oralidade na matemática escolar. A escrita marcada pelo formalismo das sentenças matemáticas e dos algoritmos hegemonicamente se faz presente na matemática escolar, essa matemática escolar que, num processo de recontextualização, toma emprestado da matemática acadêmica - a produzida pelos matemáticos na academia - sua linguagem formal, abstrata [...]. (KNIJNIK, 2010, p. 72).

Nessa perspectiva, Knijnik et al. (2012) considera a Matemática Acadêmica e a Matemática Escolar como discursos em que a produção de verdades está vinculada às relações de poder. Cada sociedade tem seu regime de verdade, sua política geral de verdade; isto é, os tipos de discurso que ela acolhe, escolhe e faz funcionar como verdadeiros. Logo, quem está autorizado a produzir e a reproduzir verdades em relação ao conhecimento matemático? Quem está autorizado produzir a verdadeira matemática? E, ainda, como essa matemática, considerada 'verdadeira' e 'legítima' será operada no currículo escolar?

Pensando nesses questionamentos, Knijnik (1997, p. 40) explica que a Matemática Acadêmica valoriza predominantemente o escrito, é produzida por um grupo:

[...] socialmente legitimado como o que pode/deve/é capaz de produzir "ciência", é a que, do ponto de vista social, vale mais. Portanto, não se trata de falar, ingenuamente, em diferentes matemáticas, mas sim considerar que tais matemáticas são, em termos de poder, desigualmente diferentes.

De forma hegemônica, na Matemática Escolar, há uma valorização da escrita, que deve seguir o rigor e os padrões estimados pela mesma, desvalorizando a matemática oral, que se encontra presente na vida diária de muitos sujeitos: pedreiros, sem-terra, agricultores, indígenas, entre outros. A tradução da linguagem matemática para a modalidade oral também apresenta conflitos, o que resulta na aversão à escrita matemática também por parte de alunos ouvintes, devido ao rigor e ao formalismo da sua escrita. O sonho de uma linguagem própria é herança do ideal de pureza (BAUMAN, 1998). Nesse contexto, arriscamo-nos a dizer que a matemática apresenta-se quase como uma segunda língua, para ouvintes.

As questões apontadas em relação à linguagem matemática no contexto de ouvintes são profícuas para repensar a aprendizagem matemática de surdos. No caso desses alunos, a matemática ocuparia a posição de quase uma terceira língua, ainda que a mesma não seja oficializada como tal. Além disso, importa destacar que a matemática de sinalização gesto-visual ainda não é valorizada enquanto possibilidade de praticar a matemática no currículo escolar da educação bilíngue para surdos.

\footnotetext{
${ }^{8} \mathrm{~A}$ educação bilíngue de surdos, de acordo com reivindicações do movimento surdo, contempla um ensino em língua de sinais, preferencialmente em escolas de surdos, com professores fluentes em Libras.
} 
A APRENDIZAGEM MATEMATICA | Daiane Kipper, Janete Inês Müller e Cláudio José de Oliveira

Concluindo esta seção, cabe ratificar que buscamos analisar enunciados que produzem o 'discurso do atraso' das crianças e jovens surdos na matemática em relação aos ouvintes de mesma faixa etária. E essa verdade, em diferentes perspectivas teóricas, é construída porque os alunos surdos, assim como outros culturalmente diferentes, não atendem a um padrão cultural pré-determinado, sobretudo pela Matemática Escolar da Modernidade.

\section{4 | CONSIDERAÇÕES FINAIS}

Neste trabalho, refletimos principalmente sobre o 'discurso do atraso' dos alunos surdos em relação aos ouvintes, tendo em vista as pesquisas que circulam nos Cadernos Cedes (número 91). Por não utilizarem a língua escrita (registro do pensamento matemático) como fazem os ouvintes, talvez, os surdos estejam sendo representados como 'atrasados' na matemática. Ao problematizarmos esse discurso, não quer dizer que estejamos concordando ou discordando dessa verdade instituída; afinal, aqui objetivamos analisar os enunciados que instituem verdades através de relações de saber-poder.

No entanto, perguntamo-nos: por que instituir o 'atraso' das crianças e jovens surdos em relação aos ouvintes? Caberia aos professores dos alunos surdos, então, 'alinhá-los aos ouvintes'? O conhecimento matemático apresentado pelos alunos surdos deve apresentar os mesmos padrões convencionais estimados para os ouvintes? Visto que o material empírico aqui analisado é divulgado em meio acadêmico, sobretudo no campo da Educação, importa refletir acerca de sua potencialidade em processos de subjetivação docente.

Questiona-se ainda se o tempo deve ser o mesmo para todos e se todos devem aprender ao mesmo tempo. Sabemos que o conhecimento disposto nas escolas provém de uma cultura ouvinte; e, mesmo sendo este conhecimento ensinado por um professor, em sua segunda língua (Libras), os alunos surdos devem aprender da mesma forma e no mesmo tempo que os ouvintes? Não propomos respostas engendradas e prescritivas, mas, sim, tensionar verdades instituídas, que pouco consideram singularidades linguísticas e culturais. 
A APRENDIZAGEM MATEMATICA | Daiane Kipper, Janete Inês Müller e Cláudio José de Oliveira

\section{Referências}

ARNOLDO JUNIOR, H.; RAMOS, Maurivan G.; THOMA, A. da S. O uso do multiplano por alunos surdos e o desenvolvimento do pensamento geométrico. Cadernos Cedes, Campinas, v. 33, n. 91, p. 387-409, set./dez. 2013. Disponível em: <http://www.scielo.br/ $\mathrm{pdf} / \mathrm{ccedes} / \mathrm{v33n} 91 / \mathrm{v} 33 \mathrm{n} 91 \mathrm{a} 06 . \mathrm{pdf}>$. Acesso em: $30 \mathrm{jul}$. 2014.

BARBOSA, H. H. Habilidades matemáticas iniciais em crianças surdas e ouvintes. Cadernos Cedes, Campinas, v. 33, n. 91, p. 333-347, set./dez. 2013. Disponível em: <http://www.scielo.br/pdf/ccedes/v33n91/ v33n91a03.pdf>. Acesso em: 30 jul. 2014.

BAUMAN, Z. O sonho de pureza. In: O mal-estar da pós-modernidade. Tradução de Mauro Gama e Cláudia Martinelli Gama. Rio de Janeiro: Jorge Zahar, 1998. p. 13-26.

CADERNOS CEDES. Campinas: Centro de Estudos Educação e Sociedade, v. 33, n. 91, 2013. Quadrimestral. Disponível em: <www.cedes.unicamp.br>. Acesso em: 30 jul. 2014.

FERNÁNDEZ-VIADER, M. del P.; FUENTES, M. Observando estratégias e buscando soluções: a resolução de operações por adolescentes surdos. Cadernos Cedes, Campinas, v. 33, n. 91, p. 369-386, set./dez. 2013. Disponível em: <http://www.scielo.br/pdf/ccedes/ v33n91/v33n91a05.pdf>. Acesso em: 25 jul. 2014.

FERNANDES, S. H.; HEALY, L. Expressando generalizações em libras: álgebra nas mão de aprendizes. Cadernos Cedes, Campinas, v. 33, n. 91, p. 349-368, set./dez. 2013. Disponível em: <http://www.scielo.br/ $\mathrm{pdf} / \mathrm{ccedes} / \mathrm{v33n} 91 / \mathrm{v} 33 \mathrm{n} 91 \mathrm{a} 04 . \mathrm{pdf}>$. Acesso em: $25 \mathrm{jul}$. 2014.

FOUCAULT, M. A ordem do discurso: aula inaugural no Collége de France, pronunciada em 2 de dezembro de 1970. Tradução de Laura Fraga de Almeida Sampaio.

4. ed. São Paulo: Edições Loyola, 1998. 79 p.

As palavras e as coisas: uma arqueologia das ciências humanas. Tradução de Salma Tannus Muchail. 8. ed. São Paulo: Martins Fontes, 1999. 422 p.

Microfísica do poder. Tradução de Roberto Machado. 16. ed. Rio de Janeiro: Edições Graal, 2001a. 295 p.

Os anormais: curso no Collége de France (1974-1975). Tradução de Eduardo Brandão. São Paulo: Martins Fontes, 2001b. 479 p.
A arqueologia do saber. Tradução de Luiz Felipe Baeta Neves. 7. ed. Rio de Janeiro: Forense, 2004. $236 \mathrm{p}$.

Segurança, território e população: curso no Collége de France (1977-1978). Tradução de Eduardo Brandão. São Paulo: Martins Fontes, 2008. 572 p.

FISCHER, R. M. B. Foucault e a análise do discurso em educação. Cadernos de Pesquisa, São Paulo, n. 114, p. 197-223, nov. 2001. Disponível em: <http://www. scielo.br/pdf/cp/n114/a09n114.pdf $>$. Acesso em: $19 \mathrm{dez}$. 2013.

KNIJNIK, G. As novas modalidades de exclusão social: trabalho, conhecimento e educação. Revista Brasileira de Educação, São Paulo, n. 4, p. 35-42, jan./abr. 1997. Disponível em: <http://anped.org.br/rbe/rbedigital/ RBDE04/RBDE04_05_GELSA_KNIJNIK.pdf $>$. Acesso em: 19 dez. 2013.

Educação matemática, currículo e diferença cultural. In: LOPES, M. C.; FABRIS E. H. (Org.). Aprendizagem \& inclusão: implicações curriculares. Santa Cruz do Sul: EDUNISC, 2010. p. 69-86.

KNIJNIK, G. et al. Etnomatemática em movimento. Belo Horizonte: Autêntica, 2012. 108 p.

KRITZER, K. L.; PAGLIARO, C. M. Matemática: um desafio internacional para estudantes surdos. Cadernos Cedes, Campinas, v. 33, n. 91, p. 431-439, set./dez. 2013. Disponível em: <http://www.scielo.br/pdf/ccedes/ v33n91/v33n91a08.pdf>. Acesso em: 19 dez. 2014.

NUNES, Terezinha. et al. Promovendo a compreensão da composição aditiva em crianças surdas. Cadernos Cedes, Campinas, v. 33, n. 91, p. 319-332, 2013. Disponível em: <http://www.scielo.br/pdf/ccedes/v33n91/ v33n91a02.pdf>. Acesso em: 19 dez. 2014.

SILVA, T. T. da. Teoria cultural e educação: um vocabulário crítico. Belo Horizonte: Autêntica, 2000. 125 p.

SKLIAR, C. Pedagogia (improvável) da diferença: e se o outro não estivesse aí? Tradução de Giane Lessa. Rio de Janeiro: DP\&A, 2003. 224 p.

VARGAS, R. da C.; DORNELES, B. V. Uma intervenção em contagem com duas crianças surdas. Cadernos Cedes, Campinas, v. 33, n. 91, p. 411-427, set./dez. 2013. Disponível em: <http://www.scielo.br/ $\mathrm{pdf} /$ ccedes/v33n91/v33n91a07.pdf>. Acesso em: 27 dez. 2014. 